\title{
Acute Appendicitis: Epidemio-Clinical and Therapeutic Aspects in Koutiala, Mali
}

\section{Mahamadou Coulibaly, ${ }^{1,2}$, Drissa Traoré1,3, Bréhima Bengaly ${ }^{1,3}$, Birama Togola ${ }^{1,3}$, Drissa Ouattara ${ }^{3}$, Nouhoum Ongoiba ${ }^{1,3}$}

${ }^{1}$ Faculty of Medicine, University of Science, Technique and Technologies of Bamako, Bamako, Mali

${ }^{2}$ Department of Surgery, Koutiala Hospital, Bamako, Mali

${ }^{3}$ Department of Surgery, University Hospital Center Point G, Bamako, Mali

Email: *cmahamadou38@yahoo.fr

How to cite this paper: Coulibaly, M. Traoré, D., Bengaly, B., Togola, B., Ouattara, D. and Ongoiba, N. (2020) Acute Appendicitis: Epidemio-Clinical and Therapeutic Aspects in Koutiala, Mali. Surgical Science, $11,216-221$

https://doi.org/10.4236/ss.2020.118024

Received: July 10, 2020

Accepted: August 17, 2020

Published: August 20, 2020

Copyright $\odot 2020$ by author(s) and Scientific Research Publishing Inc. This work is licensed under the Creative Commons Attribution International License (CC BY 4.0).

http://creativecommons.org/licenses/by/4.0/

\begin{abstract}
Purpose: To assess the epidemiological, clinical and therapeutic aspects of acute appendicitis at the Koutiala Reference Health Centre. Methods: This was a prospective study conducted in the general surgery department of the Koutiala Reference Health Centre. Patient records admitted for simple and complicated appendicitis during the period from August 1, 2017 to August 31, 2018 have been collected. Patients operated on for simple and complicated acute appendicitis were included in the study. Patients who did not have surgery were excluded. Results: We collected records of 62 patients who had surgery for simple and complicated acute appendicitis. They accounted for $11.9 \%$ of surgical procedures (n-520) and $27.3 \%$ (n-227) of surgical emergencies. The average age was 33.1 years-15.7. Men were in the majority with $72.5 \%$. Simple acute appendicitis accounted for $56.4 \%$ of cases (n-35) and complicated appendicitis $43.6 \%$ of cases (these were 16 cases of appendicular peritonitis, 09 cases of appendicular abscess and 02 cases of appendicular plastron). Therapeutically, appendectomy was performed in 58 patients. In 4 patients the appendix was completely necrotized. The average length of hospitalization was 3.3 days- 0.8 for single acute appendicites and 6 days- 2.7 for complicated appendicites. Postoperative morbidity of complicated appendicitis was $6.4 \%$ (no. 4) and mortality was zero. Conclusion: Simple acute appendicitis is more common. Laparotomy remains the only way at present. Postoperative morbidity is high in complicated appendicitis and mortality is zero.
\end{abstract}

\section{Keywords}

Appendix, Abscess, Peritonitis, Plastron, Surgery 


\section{Introduction}

Simple and complicated acute appendicitis is a frequent pathology worldwide and occupies an important place in the emergencies managed in the digestive surgery departments [1]. In Thailand [2], 2139 cases of appendectomy were performed in eight hospitals in 2006 and in France 83,400 appendectomies were performed in 2012 [3]. These pathologies generally affect young male subjects [4] [5]. Simple acute appendicitis represents $70 \%$ of these pathologies [6] [7] [8]. The diagnosis is clinical, but complementary exams such as an abdominal ultrasound and an abdominal scanner keep their place in difficult cases [5]. Appendectomy is the radical surgical treatment either by conventional laparotomy or by laparoscopic surgery. Morbidity remains high and the rate varies between $8 \%$ to $15 \%$ [9] [10]. Mortality is low [9]. For lack of data on simple and complicated acute appendicitis in the Koutiala circle, we initiated this work whose aim was to assess the epidemiological, clinical and therapeutic aspects of simple and complicated acute appendicitis at the Koutiala Reference Health Center.

\section{Methodology}

It was a prospective study carried out in the general surgery department of the Koutiala Reference Health Center. The records of patients admitted for simple and complicated acute appendicitis during the period from August 1, 2017 to August 31, 2018 were collected. Patients operated on for simple and complicated acute appendicitis were included in the study. Non-operated patients were excluded. The realization of this work required a detailed database which was validated by our scientific committee, we used for that the medical file of the patients, the register of consultation, the notebooks of the operational report. The parameters studied were age, sex, data from the clinical examination, the results of the paraclinical examinations, the etiologies, the methods of treatment and their results.

\section{Results}

We collected the files of 62 patients operated on for simple and complicated acute appendicitis. They represented $3.1 \%$ of consultations $(n=2012), 11.9 \%$ of surgical procedures $(n=520)$ and $27.3 \%(n=227)$ of surgical emergencies. The mean age of the patients was $33.1 \pm 15.7$ years with extremes of 5 and 70 years. There was a male predominance $(72.6 \%, \mathrm{n}=45)$. The sex ratio was 2.6. The symptomatology was represented by abdominal pain with $100 \%$ of cases ( $\mathrm{n}=$ $62)$, vomiting $(83.8 \%, \mathrm{n}=52)$, fever $(75.8 \%, \mathrm{n}=47)$ and stopping of materials and gases $(17.7 \%, \mathrm{n}=11)$. The duration of symptomatic evolution was 3.2 days \pm 2.5 ( $1-15$ days) for simple acute appendicitis and 6.2 days \pm 4.1 ( 1 and 20 days) for complicated appendicitis. The physical signs are noted in [Table 1]. In the blood form count (NFS) 40 patients had a leukocytosis i.e. $64.5 \%$ of the cases. Abdominopelvic ultrasound was performed in 18 patients (29.0\%). It made it possible to highlight the positions of the appendix in 7 cases (11.3\%) and the 
Table 1. Distribution of patients operated on for simple and complicated acute appendicitis in Koutiala between August 2017 and August 2018 according to physicalsigns.

\begin{tabular}{ccc}
\hline Physical signs & Number of cases & $\%$ \\
\hline Defense Right iliac fossa & 46 & 74.2 \\
Parietal contracture & 16 & 25.8 \\
Right iliac fossa wheelbase & 9 & 14.5 \\
Painful mass Right iliac fossa & 2 & 3.2 \\
Pain in Douglas's Cul de sac & 47 & 75.8 \\
Douglas' Cul de sac bulge & 25 & 40.3 \\
\hline
\end{tabular}

presence of an intraperitoneal effusion in 8 cases (12.9\%). In 3 patients (4.8\%), the ultrasound did not contribute to the diagnosis. The etiologies are presented in [Table 2]. All of our patients were operated on in emergency except the two cases of appendicular chest plate. These were cooled with medical treatment consisting of parenteral antibiotics (ceftriaxone and metronidazole) and analgesics (paracetamol combined with tramadol), ice bladder and diet for 3 days. This treatment enabled apyrexia in both patients and the relay was taken orally (amoxicillin combined with clavulanic acid) for 10 days. Surgical treatment was performed three months after cooling. Classic laparotomy was the first route for all patients. It was a Mac Burney incision for simple acute appendicitis in $37 \mathrm{pa}-$ tients $(59.6 \%)$ and a midline laparotomy for appendicular abscesses and peritonitis $(40.3 \%, \mathrm{n}=25)$. Intraoperatively we found the appendix in 58 patients (93.5\%). In 4 patients (6.4\%), the appendix was completely necrotic (03 cases of appendicular peritonitis, 01 case of appendicular abscess). The appendix was catarrhal in 25 patients $(43.1 \%)$, perforated $(24.1 \%, \mathrm{n}=14)$, phlegmonous $(25.8 \%, \mathrm{n}=15)$ and gangrenous $(6.9 \%, \mathrm{n}=4)$. The appendix was in the iliac position in 35 patients $(60.3 \%)$, pelvic $(20.7 \%, \mathrm{n}=12)$, mesocecal $(10.3 \%, \mathrm{n}=6)$, retro cecal $(6.9 \%, \mathrm{n}=4)$ and subhepatic $(1.7 \%, \mathrm{n}=1)$. The appendectomy was performed in 58 patients (93.5\%) including two delayed cases (02 appendicular chest plates). It was associated with burial in 35 patients and cleansing of the peritoneal cavity and drainage in 25 patients. For cases where the appendix was completely necrotic, we were content with the toilet and the drainage of the right iliac fossa [Table 3].

Analysis of the effusion taken intraoperatively was done in 23 patients (37.1\%). She objectified Escherichia coli in 18 patients, streptococcus in 4 patients and bacteroides in 1 patient. The antibiotics used intraoperatively were the combination of third generation cephalosporin (ceftriaxone) and imidazoles (metronidazole). The postoperative consequences were simple in $93.6 \%$ of cases. The postoperative morbidity of simple acute appendicitis was zero and it was $6.4 \%$ of cases $(n=4)$ for complicated appendicitis. These were 01 cases of postoperative peritonitis which was reoperated, 01 case of external digestive fistula 
Table 2. Distribution of patients operated for simple and complicated acute appendicitis in Koutiala between August 2017 and August 2018 according to etiologies of pathologies.

\begin{tabular}{ccc}
\hline Etiologies & Number of cases & $\%$ \\
\hline Simple acute appendicitis & 35 & 56.5 \\
Appendicular abscess & 9 & 14.5 \\
Appendix plate & 2 & 3.2 \\
Appendicular peritonitis & 16 & 25.8 \\
Total & 62 & 100 \\
\hline
\end{tabular}

Table 3. Distribution of patients operated for simple and complicated acute appendicitis in Koutiala between August 2017 and August 2018 according to surgical treatment.

\begin{tabular}{lccc}
\multicolumn{1}{c}{ Pathologies } & Number of cases & Surgical technique & $\%$ \\
\hline Acute appendicitis & 37 & Appendectomy & 59.7 \\
Appendicular abscess & & & \\
Appendix seen & 8 & Appendectomy + Toilet & 12.9 \\
Completely necrotic appendage & 1 & Toilet + Drainage & 1.6 \\
Appendicular peritonitis & & Appendectomy + Toilet & 21.0 \\
Appendix seen & 13 & + Drainage & \\
Completely necrotic appendage & 3 & Toilet + Drainage & 4.8 \\
\hline
\end{tabular}

which was put under observation with medical treatment which made it possible to have spontaneous closure after the 11th postoperative day and 02 cases parietal suppurations which were treated by local care combined with antibiotic therapy. The average length of hospital stay was 3.3 days \pm 0.8 ( 3 - 7 days) for simple acute appendicitis and 6 days \pm 2.7 (3 - 14 days) for complicated appendicitis. We have had no deaths. The course at 3 months of follow-up was normal in 48 patients ( 30 cases of simple acute appendicitis and 18 cases of complicated appendicitis) and the rest were lost to follow-up.

\section{Discussion}

Simple and complicated acute appendicitis occupies the first place of surgical emergencies in our service as it is brought by several authors [10] [11]. Among these pathologies, simple acute appendicitis is the most frequent with $56.4 \%$ of cases. In the Western series we find the same result with a slightly higher frequency which varies between $65 \%$ to $75 \%$ [6] [8]. In this study as in the literature, appendicitis affects young subjects much more preferably of male sex [4] [5] [12] [13]. Consultations beyond 6 days are observed in 27 patients. Appendi- 
citis may have been confused with malaria syndrome or salmonellosis. However, this long delay could be explained by self-medication in our context. This delay in consultation in this study explains the high rate of complicated appendicitis which is $43.5 \%$. The symptomatology of appendicitis is manifested by pain typically localized in the right iliac fossa but sometimes more diffuse and fever [1]. Abdominal pain remains the constant sign in this study, it is associated with vomiting, fever and hyperleukocytosis in most of the patients. This associative table should lead to imaging exams, of which ultrasound and scanner are the most proposed. Among these exams, only ultrasound is feasible in our circle. And it was only done in 18 patients. This is linked to its permanent unavailability, especially at late hours of the night, but also to the quality of the result, which is very often considered unreliable due to the lack of qualified personnel; this is why in three patients the abdomino-pelvic ultrasound performed did not contribute to the diagnosis and these patients were operated on the result of clinical data. In the literature, some authors emphasize the conservative treatment of simple acute appendicitis with antibiotic therapy [12]. This strategy is difficult to apply in our context because of the lack of equipment and qualified personnel for surveillance. Reason for which all our patients were operated in emergency except the two cases of appendicular plastron which were cooled. The approach was conventional either through the Mac Burney incision or through the middle laparotomy. This result is different from that of the capital of our country (Bamako) where the treatment of appendicitis is often done by laparoscopic surgery [14]. The burial of the appendicular stump is not systematic, it depends on the state of the lower appendicular and the cecal wall. This is why we only realized it in simple acute appendicitis. Cleansing of the peritoneal cavity and drainage are associated with the treatment of complicated appendicitis and, moreover, they were the only therapeutic methods for the four cases of total necrosis of the appendix. The post-operative morbidity of $6.4 \%$ of complicated appendicitis would be linked to a delay in consultation, therefore diagnosis rather than surgery; explaining an average hospital stay of 6 days in these patients of up to 14 days. The same observation is made by the authors [4] [9] [10]. No case of death was noted in our study. The limits of this work were the lack of financial means of the patients, the insufficiency of technical platform and the lack of qualified personnel.

\section{Conclusion}

Simple and complicated acute appendicitis is frequent in our department. Young male subjects are the most affected. Simple acute appendicitis is more common. Laparotomy remains the only approach currently in Koutiala. Postoperative morbidity is high in complicated appendicitis.

\section{Conflicts of Interest}

The authors declare no conflicts of interest regarding the publication of this paper. 


\section{References}

[1] Millet, I., Alili, C., Pages, E., Doyon, C., Merigeaud, S. and et Taourel, P. (2012) Infection de la fosse iliaque droite. Journal de radiologie diagnostique et interventionnelle, 93, 471-482. https://doi.org/10.1016/j.jradio.2012.04.003

[2] Nongyao, K., Mette, N., Henrik, T., Henrik, C.S., Silom, J. and Virasakdi, C. (2006) Risque d'infection du site opératoire et efficacité de la prophylaxie antibiotique: une étude de cohorte de patients souffrant d'appendicectomie en Thailande. BMC Infectious Diseases, 6, 4-6.

[3] Philippe, O. and Marie, C.M. (2014) La longue diminution des appendicectomies en France. Études et resultants, 868, 1-6.

[4] Mitsingou, J.C. and Gom, P. (1994) Reflexion sur la pathologie appendiculaire. A propos de 48 cas colligés à la Clinique Chirurgicale des Armées de Pointe-Noire (Congo). Médecine d’ Afrique Noire, 41, 117-119.

[5] Amadou, A., N'timon, B., Marouane, A. and Bichri, M. (2013) Echographie et tomodensitométrie dans les appendicites retro caecales. Pan African Medical Journal, 14, 1-6. https://doi.org/10.11604/pamj.2013.14.117.2169

[6] Pariente, A. and Bonnefoy, O. (2014) Maladie de l'appendice. EMC-Traité de médecine Akos, 9, 1-5. https://doi.org/10.1016/S1634-6939(06)75341-8

[7] Corinne, V. and Michèle, B. (2017) Épidémiologie descriptive des appendicites en France: Faut-il revoir la physiopathologie des appendicites aiguës? Bull. Acad. Natle Méd, 201, 4-6. https://doi.org/10.1016/S0001-4079(19)30505-9

[8] Emil, S., Laberge, J.M., Mikhail, P., Baican, L., Flageole, H., Shaw, K., et al. (2003) Appendicitis in Children: À Ten-Year Update of Therapeutic Recommendations. Journal of Pediatric Surgery, 38, 236-242. https://doi.org/10.1053/jpsu.2003.50052

[9] Podevin, G., Barussaud, M., Leclair, M.D. and Heloury, Y. (2005) Appendicite et péritonite appendiculaire chez l'enfant. EMC (Elsevier SAS, Paris). Pédiatrie, 10, 4-18. https://doi.org/10.1016/S1245-1789(05)45000-3

[10] Allode, S.A., Mensah, A.E., Hodonou, M.A., Mehinto, D.K., Dossou, F.M., et al. (2013) Résultat de l'appendicectomie au centre hospitalier départemental du Bourgou-Alibori à Parakou au nord-est du Bénin: Étude de 164 cas. Médecine d Afrique noire, 60, 1-10.

[11] de Santé, H.A. (2012) Appendicectomie. Eléments décisionnels pour une indication pertinente. Note de cadrage. Saint-Denis La Plaine HAS, 9-12.

[12] El Ahmed, K., Mohamed, L., El Rachid, B. and Abdessamad, A. (2015) Appendicite aigue non compliquée: Y a-t-il une place pour le traitement conservateur. Pan African Medical Journal, 21, 1-6. https://doi.org/10.11604/pamj.2015.21.144.6045

[13] Ngowe, M., Bissou, J., Mahop, Atangana, R., Eyenga, V.C., Pisoh-Tangnym, C. and Sosso, A.M. (2008) Aspects cliniques actuels des appendicites aiguës de l'adulte à Yaoundé, Cameroun. Bulletin de la Société de pathologie exotique, 101, 398-399. https://doi.org/10.3185/pathexo3148

[14] Sanogo, Z.Z., Koita, A.K., Diakité, S., Koumaré, S., Keita, S., Ouattara, M.A., Togo, S., Camara, M., Doumbia, D. and Sangaré, D. (2012) Appendicectomie par coeliochirurgie à Bamako. Journal africain d'Hépato-Gastroenterologie, 6, 298-302. https://doi.org/10.1007/s12157-012-0419-y 